\title{
En homenatge a Julie Graham (1945-2010)
}

\author{
Antònia Casellas \\ Universitat Autònoma de Barcelona. Departament de Geografia \\ antonia.casellas@uab.cat
}

Recepció: febrer de 2011

Acceptació: març de 2011

La teoria ha adquirit una nova relació amb l'acció: comprendre el món vol dir canviar-lo.

J.K. Gibson-Graham i G. Roelvink (2010). «An Economic Ethics for the Anthropocene». Antipode, 41 (s1), 342

La mort sobtada, el dia 5 d'abril de 2010, de Julie Graham va suposar una gran pèrdua, no només per a l'àmbit de la geografia econòmica, marxista i de gènere, sinó també per a l'activisme social. Julie Graham era una acadèmica poc convencional que, alhora, exemplificava el millor que l'àmbit acadèmic hauria d'oferir: la capacitat d'analitzar amb esperit crític —és a dir, amb voluntat de canviar el món per millorar-lo- idees àmpliament acceptades per identificarne mancances i conceptualitzar noves propostes orientades a l'acció. Per això, ben mirat, Julie Graham era, abans de tot, una activista. Una activista ben informada i amb voluntat analítica que alimentava el seu intel.lecte combinant l'àmbit de la geografia econòmica amb la crítica marxista i de gènere, en un esforç constant per repensar el que és i, encara més important, el que hauria de ser això que se'n diu "economia» $\mathrm{i}$ «desenvolupament econòmic».

Tot i que feia temps que lluitava contra un càncer, Graham no va morir a casa, sinó a causa d'unes complicacions a la tràquea que li van bloquejar la respiració en un vol des d'Austràlia quan ja havia arribat als EUA. Les condicions de la seva mort, tot i que van ser tràgiques, també constitueixen un exemple de la voluntat de superació i treball de Graham, que, malgrat els problemes derivats de la seva malaltia i dels tractaments que seguia, continuava viatjant $\mathrm{i}$ treballant sense defallir. Més enllà de les aportacions acadèmiques que va fer, del seu esperit lluitador i treballador, va ser també un model d'inspiració per a tothom.

Graham es va graduar amb un B.A. en anglès a Smith College (una universitat privada i liberal exclusiva per a dones) l'any 1968, i després va completar 
els estudis amb un doctorat en geografia econòmica a Clark University el 1984. Viatgera incansable, amb tot, la seva vida d'estudiant i professional va girar al voltant de l'Estat de Massachusetts. Després d'haver acabat el doctorat a Clark, el mateix any es va incorporar al Departament de Ciències de la Terra, a la Universitat de Massachusetts (Amherst), com a professora de Geografia. En el moment de la seva mort, era associada al càrrec de cap de departament. Conseqüent $\mathrm{amb}$ la seva voluntat d'influir més enllà de l'àmbit acadèmic, a Amherst, Graham era també membre actiu del Center for Popular Economics (http://www.populareconomics.org/Index.html). Aquest centre és una organització sense ànim de lucre fundada l'any 1978 per especialistes en economia. L'objectiu de l'organització és examinar les causes profundes de la desigualtat econòmica i la injustícia, inclosos els sistemes d'opressió per motius de raça, classe, gènere, nació i ètnia.

Molts dels companys de Graham coincideixen a considerar que Julie era una visionària. Aquesta facultat segurament provenia de la seva necessitat de no acomodar-se ni encaixonar-se en un grup acadèmic específic. Per això hi ha qui la defineix com a economista política, uns altres com a marxista, com a neomarxista, com a postestructuralista, com a feminista, com a radical i com a activista.

Graham va tenir clar des d'un principi que l'economia no es pot interpretar separadament de la política ni de les relacions de poder. La seva crítica a les anàlisis dels economistes clàssics la van situar inicialment al costat dels marxistes, però, un cop estudiada i aprofundida l'anàlisi marxista, Graham va entreveure clarament que el marxisme patia un gran mal: l'essencialisme. L'article que va escriure l'any 1988 a Antipode s'ha convertit en un clàssic'. En la mesura que la classe social o lluita de classes articula l'anàlisi marxista i aquesta categoria es converteix en la base fonamental per fer l'anàlisi de la realitat, queden excloses moltes més perspectives que poden aportar llum a una realitat complexa. Així, des del pensament feminista i postestructuralista, Graham va buscar estratègies interpretatives noves per al procés de transformació econòmica dels territoris, amb les repercussions espacials, socials i ambientals que això comportava.

Al llarg de la seva vida acadèmica, Julie Graham va publicar més de cinquanta treballs al costat de Katherine Gibson. Ho van fer d'una manera tan creativa com poc convencional en el món universitari, tot sovint massa preocupat per la visibilitat individual. Julie Graham i Katherine Gibson, amb Graham treballant des dels EUA i Gibson des d'Austràlia, van crear un únic individu pensant, identificat amb un pseudònim subjecte acadèmic que simbolitza la seva estreta i creativa col-laboració: JK Gibson-Graham. Entre les seves publicacions més emblemàtiques, hi ha The End of Capitalism (as we knew it), publicat el 1996, i A Postcapitalist Politics, publicat deu anys més tard, el 2006. Al final d'aquest article, s'hi recull una llista de les publicacions més rellevants de Graham-Gibson.

1. J. Graham (1988), «Post-modernism and Marxism», Antipode, 20 (1), 60-66. 
A The End of Capitalism, Gibson-Graham utilitzen les teories feministes i la teoria Queer per discutir el poder hegemònic del discurs econòmic capitalista. Qüestionant la visió del sistema capitalista com a necessari i «naturalment» hegemònic, Gibson-Graham apunten que la crítica marxista el que fa és aportar legitimació al capitalisme, en presentar-lo com a dominant. Amb la seva crítica, Gibson-Graham, d'una banda, ataquen la meganarrativa capitalista i, de l'altra i més important, desenvolupen la noció de «l'economia de la diferència». L'objectiu últim de Gibson-Graham és poder imaginar espais econòmics alternatius $\mathrm{i}$, gràcies a això, poder-los identificar dins les pràctiques econòmiques quotidianes existents, per poder estudiar-los i fomentarlos. Una imatge de gran abast que il.lustra aquest punt es troba en la seva publicació del 2006, A Postcapitalist Politics. Es tracta de la imatge d'un iceberg, la punta visible del qual mostra les transaccions en el mercat formal que analitza la teoria econòmica tradicional. Per sota d'aquesta punta, hi ha, però, una infinitat d'altres pràctiques existents de les quals no es parla. Són transaccions fora del mercat que inclouen treball no remunerat o remunerat de manera alternativa, però que, de fet, són contribucions a l'economia, com la que fan les àvies i els avis que tenen cura dels néts i les nétes perquè els pares i les mares puguin formar part de la força de treball, o la del camperol que treballa de franc per ajudar el seu veí.

Aquesta línia de pensament, desenvolupada juntament amb la seva col.laboradora Katherine Gibson, les va portar a formular el que anomenaven una "política postcapitalista», entesa com un espai de reflexió i d'acció on els diferents sistemes econòmics i relacions que no són part del sistema capitalista tradicional es noten, es fan visibles, se'ls dóna suport i se'ls promou. Amb aquest objectiu, van fundar el Community Economies Collective Project (http://www.communityeconomies.org/), que té com a voluntat: 1) generar una comprensió més àmplia del que és l'economia; 2) posar de relleu l'abast i la contribució de l'economia submergida i alternativa; 3) teoritzar sobre l'economia i la comunitat com a llocs de possibilitat; 4) construir alternatives econòmiques sostenibles no capitalistes; 5) fomentar l'experimentació ètica de l'economia, i 6) generar col-laboracions entre activistes, acadèmics i agents socials.

En els darrers anys, Graham-Gibson, en el seu esforç continuat per no encabir-se en un marc acadèmic determinat — tan còmode i ben considerat en l'àmbit acadèmic, com endogàmic i limitador del pensament lliure i creatiu-, identifiquen el concepte d'Antropocè, del camp de la geologia, per apropar-nos a una ontologia posthumanista. Parteixen del fet que, tal com va anunciar la Societat Geològica de Londres el 2008, en el darrer segle, els éssers humans hem tingut un impacte tan gran i devastador en el món que fa que ens convertim en la força ecològica de canvi més extraordinària del planeta. Per això cal dir que hem entrat en una nova era geològica, que anomenen Antropocè. Des d'aquesta perspectiva, Graham-Gibson consideren que la nostra capacitat destructora i els efectes devastadors i irreversibles que provoquem ens han d'empènyer a la comprensió que vivim en un món on els éssers vius i no vius 
ens trobem entrelligats. Perquè això es comprengui i s'accepti ontològicament i psicològicament, cal que es produeixi un canvi radical de paradigma, que ens ha de traslladar des d'un model humanista, centrat en les necessitats de l'espècie humana, fins a un model posthumanista, en què els humans ens percebem com una peça més d'un puzle complex d'entitats vives i no vives. Aquest nou paradigma s'ha de fonamentar en una nova ètica, que anomenen «l'ètica econòmica per a l'Antropocè». Partint del fet que la realitat és molt més rica que el que els acadèmics normalment perceben, en el seu article publicat l'any $2010 \mathrm{a}$ Antipode, Graham-Gibson, juntament amb Roelvink, documenten pràctiques ètiques de l'economia que ja existeixen i que impliquen un reconeixement del «ser-en-comú» dels éssers humans amb el món. Per concloure l'article, GibsonGraham i Roelvink assenyalen que el paper dels acadèmics ha de canviar. Estem en un període tan diferent que les velles fórmules ja no serveixen. Ara, quan fem recerca, ja no es tracta d'entendre la realitat. La recerca acadèmica a partir d'ara ha de ser activisme, ha d'obrir-se cap al que es pot aprendre a partir del que ja està passant a la realitat.

Si és difícil ubicar Julie Graham en un grup acadèmic específic, activistes, companys acadèmics i estudiants coincideixen a parlar de la calidesa, de l'entusiasme, de la creativitat i de l'originalitat de la seva persona. La seva mort prematura deixa un buit que no es pot reemplaçar, però el treball que va realitzar, la seva inspiració i la seva guia són un llegat irrefutable.

\section{Publicacions de Julie Graham i Katherine Gibson amb el pseudònim J.K. Gibson-Graham}

\section{Libres}

Gibson-Graham, J.K. (1996). The End of Capitalism (As We Knew It): A Feminist Critique of Political Economy. Oxford UK i Cambridge USA: Blackwell.

- (2006). The End of Capitalism (As We Knew It): A Feminist Critique of Political Economy «With New Introduction». Minneapolis: University of Minnesota Press.

- (2006). A Postcapitalist Politics. Minneapolis: University of Minnesota Press.

Gibson-Graham, J.K; Resnick, S. i WolfF, R. (eds.) (2000). Class and its Others. Minneapolis: University of Minnesota Press.

- (2001). Relpresenting Class: Essays in Postmodern Marxism. Durham N.C.: Duke University Press.

\section{Capitols de llibre}

Gibson-Graham, J.K. (2002). «Beyond global vs. local: economic politics outside the binary frame». A: Herod, A. i Wright, M. (eds.). Geographies of Power: Placing Scale. Oxford: Blackwell Publishers, 25-60.

- (2002). «Situating migrants in theory: the case of Filipinos migrant contract construction workers». A: Aguilar Jr, F.V. (ed.). Filipinos in Global Migrations: At Home in the World? Manila: Philippine Migration Research Network and Philippines Social Science Council, 39-59. 
- (2003). «The economy, stupid!». A: Barnes, T.; Peck, J.; Tickell, A. i Sheppard, E. (eds.). Reading Economic Geography. Oxford i Malden MA: Blackwell, 72-87.

- (2004). «Economy». A: Bennett, T.; Grossberg, L. i Morris, M. (eds.). New Keywords A Revised Vocabulary of Culture and Society. Oxford i Malden MA: Blackwell Publishers, 94-97.

- (2005). «Building community economies: Women and the politics of place». A: Harcourt, W. i Escobar, A. (eds.). Women and the Politics of Place. Bloomfield Connecticut: Kumarian Press, 130-157.

- (2007). "Cultivating subjects for a community economy». A: Barnes, T.; Peck, J.; Sheppard, E. i Tickell, A. (eds.). Politics and Practice in Economic Geography. Londres: Sage, 106-118.

- (2007). «Surplus possibilities: post-development and community economies». A: ZiaI, A. (ed.). Exploring Post-Development: Theory and Practice, Problems and Perspectives. Londres: Routledge, 207-235.

G. Gibson-Graham, J.K. i Roelvink, G. (2009). «Social innovation for community economies». A: MacCallum, D.; Moulaert, F.; Hillier J. i Vicari, S. (eds.). Social Innovation and Territorial Development. Londres: Ashgate, 32-51.

- (2010). «An Economic Ethics for the Anthropocene». A: Castree, N.; Wright, M.; Larner, W.; Heynen, N. i Chatterton, P. (eds.). The Point is to Change It: Geographies of Hope and Survival in an Age of Crisis. Londres: Wiley-Blackwell.

\section{Articles en revistes acadèmiques}

Gibson-Graham, J.K. (2004). «Area studies after post-structuralism». Environment and Planning $A, 36,405-419$.

- (2004). "The violence of development: two political imaginaries». Development: Journal of the Society for International Development, 47 (1), 27-34.

- (2005). «Dilemmas of theorizing class». Rethinking Marxism, 17, 1, 39-44.

- (2005). «Surplus possibilities: post-development and community economies». Singapore Journal of Tropical Geography, 26 (1), 4-26.

- (2005). «Traversing the fantasy of sufficiency: A response to Aguilar, Kelly, Laurie and Lawson». Singapore Journal of Tropical Geography, 26 (2), 119-126.

- (2006). "Imagining and enacting a post-capitalist feminist economic politics: A response to Hester Eisenstein». Women's Studies Quarterly, 34 (1 i 2), 72-78.

— (2006). "Mekan tabanli küreselle me”: Devrim için yeni bir tahayyül» [«Placebased globalism: A new imaginary of revolution». Traducció del turc feta per Hande Kesgin]. Birikim: Aylik Sosyalist Kültür Dergisi, 205-206, 52-55.

- (2008). "Diverse Economies: Performative Practices for "Other Worlds" . Progress in Human Geography, 32 (5), 1-20.

- (2008). «Place-based globalism': a new imaginary of revolution». Rethinking Marxism, 20, (4), 659-664.

Gibson-Graham, J.K. i Cameron, J. (2007). «Community enterprises: Imagining and enacting alternatives to capitalism». Social Alternatives, 26, (1), 20-25.

Gibson-Graham, J.K. i Roelvink, G. (2009). «A Postcapitalist Politics of Dwelling». Australian Humanities Review, 46 (mayo), 145-158.

- (2010). «An Economic Ethics for the Anthropocene». Antipode, 41 (s1), 320-346. 